\title{
Assessing the role of $\beta$-ocimene in regulating foraging behavior of the honey bee, Apis mellifera
}

\author{
Rong MA ${ }^{1}$, Ulrich G. MuelleR ${ }^{1}$, Juliana Rangel ${ }^{2}$ \\ ${ }^{1}$ Section of Integrative Biology, The University of Texas at Austin, 1 University Station C0990, Austin, TX 78712, USA \\ ${ }^{2}$ Department of Entomology, Texas A\&M University, 315 Minnie Belle Heep, 2475 TAMU, College Station, TX 77843 , \\ USA
}

Received 26 December 2014 - Accepted 3 July 2015

\begin{abstract}
The larval pheromone (E)- $\beta$-ocimene (EBO) inhibits worker ovary development and accelerates the behavioral transition from nursing to foraging in the honey bee, Apis mellifera. Because EBO diffuses throughout the hive, it has been hypothesized that honey bee workers can use it to indirectly assess brood abundance. Here, we evaluate this hypothesis by testing whether EBO plays a role in the regulation of worker foraging activity. We exposed paired colonies to a pulse of either synthetic $\beta$-ocimene or paraffin oil control and recorded the subsequent number of pollen and non-pollen foragers returning to the colony. Exposure to synthetic $\beta$-ocimene moderately but significantly increased overall foraging activity, but not pollen foraging. For pollen foraging, the effect of pheromone treatment was the greatest directly after pheromone exposure.
\end{abstract}

\section{Apis mellifera / $\beta$-ocimene / honey bee foraging / synthetic pheromone / volatility}

\section{INTRODUCTION}

Many insect species communicate using pheromones, the production of which can elicit both short-term and long-term responses in physiology and behavior in conspecific recipients of pheromone cues. The European honey bee (Apis mellifera) has a particularly complex, nuanced pheromonal language used to mediate diverse physiological and behavioral responses in colony members, including nest defense and cooperative brood care in the worker caste, and reproductive dominance in the queen caste (Le Conte and Hefetz 2008). Pheromones in honey bees often occur as multi-component blends (Pankiw 2004). These blends regularly require all chemical

Electronic supplementary material The online version of this article (doi:10.1007/s13592-015-0382-x) contains supplementary material, which is available to authorized users.

Corresponding author: R. Ma, rong.ma@utexas.edu Manuscript editor: Monique Gauthier components to be present in specific proportions in order to affect behavior and physiology (Pankiw 2004), although individual pheromone components can sometimes produce separate or partial effects on their own. As such, the behavioral and physiological effects of pheromones on honey bees are considered an emergent property of a pheromone blend, which cannot be produced by its individual components alone (Pankiw 2004). Pheromones can also act as contextdependent signals, varying in their spatial and temporal distribution, synergizing with each other, and targeting multiple receivers in a colony (Slessor et al. 2005; Le Conte and Hefetz 2008; Kocher and Grozinger 2011).

A few pheromone blends have been studied in the context of honey bee foraging behavior. One of the best resolved is brood pheromone (BP), which is composed of 10 esters with low volatility: methyl and ethyl esters of linoleate, linolenate, oleate, palmitate, and stearate (Le Conte et al. 1989, 1990). BP is produced by honey bee larvae at all stages, but the amount produced and the 
relative proportion of the esters in the blend vary with larval age (Le Conte et al. 1994; Metz et al. 2010). Nurse bees perform a suite of brood care behaviors in response to BP, some of which are attributable to single ester components or subsets of esters from the BP blend (Pankiw 2004). The full 10-component blend of BP has been shown to increase the proportion of pollen foraging to nonpollen foraging workers (Pankiw and Rubink 2002; Sagili et al. 2011). In addition to eliciting nursing and foraging behaviors, BP causes longterm changes in physiology, such as modulating the worker transition from nursing to foraging and inhibiting ovary development (Le Conte et al. 2001; Pankiw 2004). These important physiological effects can only be produced when all BP components are present in specific proportions - a synergistic property of the pheromone. Furthermore, because reproductive division of labor and cooperative brood care are central to honey bees as highly eusocial insects (Bourke 2011), larval pheromones that modulate ovary development and nursing behavior may play an important role in maintaining sociality in this species.

Despite BP's important role in a honey bee colony, the mechanisms by which BP releases shortterm increases in pollen foraging are not well characterized (but see Le Conte et al. 2001; Alaux et al. 2009). BP components are considered non-volatile, so it is assumed that bees need to come in direct contact with BP in order for it to affect worker behavior and physiology (Pankiw 2004; Muenz et al. 2012). Nurse workers constantly make contact with larvae during brood care and feeding behaviors, including feeding larvae with glandular secretions produced from transformed pollen stores (Crailsheim et al. 1992; Pankiw et al. 1998). During brood care activities, nurses thus have the opportunity to directly assess the level of BP from multiple larvae, as well as assess the colony-wide availability of stored pollen resources. Although foragers do not engage in brood care, there is evidence that they can also be influenced by exposure to BP. For example, when exposed to synthetic BP, individual foragers show dose-dependent changes in sucrose response thresholds, which are correlated with pollen foraging preferences (Pankiw et al. 1998; Pankiw and Page 2001; Sagili et al. 2011). Similarly, when colonies are exposed to synthetic BP, foragers increase pollen foraging but not nectar foraging activity (Pankiw et al. 1998; Pankiw and Rubink 2002; Metz et al. 2010). Previous studies have also shown that pollen foraging effort is negatively correlated with the amount of stored pollen resources but positively correlated with the number of brood present in the hive (Allen and Jeffree 1956; Fewell and Winston 1992; Fewell and Page 1993). Furthermore, in the absence of brood, individual foragers can readily switch from pollen to nectar foraging (Free 1967). Together, these studies show that the level of pollen foraging in a colony depends on the foragers' assessment of the availability and consumption rate of pollen resources. However, the mechanism by which forager honey bees sense the levels of stored pollen or BP in a natural colony setting remains unclear.

Honey bee larvae also emit $(E)$ - $\beta$-ocimene (EBO), a volatile monoterpene produced primarily by young larvae in their first through third instar (Maisonnasse et al. 2009, 2010). Like other volatile pheromones, EBO can dissipate quickly. BP and EBO are chemically distinct larval pheromones, but they can induce similar physiological and behavioral changes in nurse bees. For instance, Maisonnasse et al. $(2009,2010)$ showed that EBO partially suppresses worker ovary development and accelerates the behavioral transition from nursing to foraging, which is similar to the long-term physiological effects of low doses of BP. This transition is delayed in the presence of high doses of BP, however. Despite these similarities, EBO departs from previously investigated brood pheromones in two important ways. First, EBO is highly volatile, which means that it can quickly diffuse throughout the hive, thus removing the need for foragers to come in close physical contact with brood to affect their behavior. Second, EBO is comprised of a single compound, which means that its effects are not dependent on a blend of multiple compounds to elicit a behavioral effect. Maisonnasse et al. (2010) therefore hypothesized that multiple worker castes could potentially assess the concentration of EBO in a colony - possibly as an indication of the number of young brood in the hive - and adjust their behaviors accordingly. Recently, Traynor et al. (2015) showed that, in colonies without brood, synthetic ocimene is able to increase total foraging by approximately $35 \%$ and the proportion of pollen 
foraging by $10 \%$. However, the effects of varying ambient EBO levels on hive behavior have yet to be explored in colonies with brood.

In this study, we tested whether non-nursing workers can detect EBO directly and, if so, whether non-nursing workers detect and respond to EBO by modulating their behavior. Specifically, we exposed colonies to a pulse of synthetic EBO and measured the resulting colony-wide foraging activity over the course of $4 \mathrm{~h}$. Because EBO can diffuse throughout the hive and is produced by young brood with specific nutritional demands, we hypothesized a priori that treating colonies with EBO would increase overall foraging activity, especially foraging for pollen. We found that exposure to 1-h pulses of EBO moderately increased non-pollen foraging, but not pollen foraging.

\section{MATERIAL AND METHODS}

\subsection{Honey bee colonies}

All experiments and hive manipulations were conducted in July and August 2013 at the Texas A\&M University Honey Bee Facility, located at the Riverside Campus, College Station, Texas ( $\left.30^{\circ} 6^{\prime} \mathrm{N} ; 96^{\circ} 32^{\prime} \mathrm{W}\right)$. Two trials were performed on 1-14 July and 24 July -8 August. All honey bee colonies were allowed to forage freely in the environment and had access to the same resources: water from a large nearby pond, nectar and pollen from surrounding farms, and natural forage. All bees used in this study were of mixed European races, and their respective queens were naturally mated.

For each of two trials, four honey bee "nucleus" colonies were created from source colonies following standard beekeeping techniques (Winston 1987). Briefly, approximately 5000 workers and a caged queen were introduced into a plastic 5-frame hive box and the entrance to the hive was sealed. Each hive was provisioned with two frames containing ample honey and pollen resources, two frames of mixed-age brood, and one empty frame to allow the colonies to expand, if needed. The nucleus boxes were modified in two ways: a wooden landing strip was added to the hive entrance to facilitate the counting of foragers entering the hive, and a petri dish-sized flap was cut into the side of the box to allow pheromone application with minimal disturbance. All nucleus colonies were placed in an airconditioned room $\left(\sim 23^{\circ} \mathrm{C}\right)$ for $24 \mathrm{~h}$ to allow them to assimilate to the new hive environment. The next day, the hives were moved to a new location approximately $100 \mathrm{~m}$ away from the source colonies and were placed in a row spaced approximately $1 \mathrm{~m}$ apart. Tree branches were placed in front of the hive entrances prior to releasing the bees to encourage them to acclimate to the new hive location and to avoid drifting. All queens were released from their cages 2-4 days prior to start of the experiment and were allowed to roam freely around the hive and oviposit.

To estimate the number of bees and food resources present in each hive, we examined all frames individually by taking them out and overlaying a gridded frame consisting of $1 \mathrm{in}^{2}$ squares. To assess the initial size of each experimental colony, we counted the number of squares that were covered by workers and by comb containing brood, honey, or pollen prior to the start of each trial. At the beginning of each experiment, the amount of brood, stored food resources, and empty space were equalized in each hive to the initial levels to ensure consistency throughout the course of the experiment. The brood measurements combined the amount of open and capped brood present.

\subsection{Experimental design}

Each day of the experiment, pairs of hives were randomly assigned to either a synthetic $\beta$-ocimene pheromone treatment or a paraffin oil control treatment. To minimize colony disturbance, treatments were placed in a petri dish, covered with wire mesh (to avoid direct worker contact with chemicals), and inserted directly under frames using a small trap door cut into the bottom of the hive box. The pheromone treatment consisted of $1 \mathrm{~mL}$ of synthetic $\beta$-ocimene (mixture of isomers, Sigma-Aldrich) mixed with paraffin oil for a total volume of $2 \mathrm{~mL}$ while the control treatment was $2 \mathrm{~mL}$ of paraffin oil alone.

Treatments were placed in each hive in a pair at the same time for $1 \mathrm{~h}$ and then removed. The number of foragers returning to the hive was counted for $5 \mathrm{~min}$ immediately after the removal of each petri dish and then again each hour thereafter for a total of $4 \mathrm{~h}$. We recorded the time at which a pheromone treatment was placed in the hive, the time when it was removed, and the time when observations of foragers returning to the hive were made. Thus, it was possible to calculate the elapsed time between foraging observations and the 
removal of the petri dish containing pheromone or control treatments.

All returning bees were counted as either pollen foragers or non-pollen foragers based on whether they carried pollen in their hind corbiculae. Because foragers were only scored for the presence or absence of pollen, foragers that returned without pollen could not be distinguished between nectar and water foragers. Observations were made on sunny days during the same times each day (0900 to 1700 hours). In the first trial (1-14 July 2013), observations were made only in the afternoon (1300-1700 hours). During the second trial (24 July-8 August 2013), observations were made in the morning and the afternoon to collect more information and to avoid confounding variation in foraging rates due to time of day with response to pheromone treatment. Data were collected on 16 separate days for a total of 180 observations for each treatment. Observations of returning foragers were made by $\mathrm{RM}$, who was not blinded to a colony's treatment condition during data collection.

\subsection{Synthetic pheromone and chemical analysis}

The synthetic ocimene used in this study ( $\geq 90 \%$, Sigma-Aldrich) was a mixture of isomers. $(E)-\beta$ ocimene was likely present in at least $25 \%$ of the total ocimene used (discussed below). To determine the amount of ocimene that evaporated into the hive, a mixture of ocimene was compared before and after evaporating for the same duration and average temperature inside the colony $\left(35^{\circ} \mathrm{C}\right)$ as was done during the experiment. To treat colonies, a dish with a mixture of $1 \mathrm{~mL}$ of ocimene and $1 \mathrm{~mL}$ paraffin oil $(2 \mathrm{~mL}$ total volume) was inserted into an empty hive box and allowed the mixture to evaporate for $1 \mathrm{~h}$ at $35^{\circ} \mathrm{C}$. Then, the remaining mixture was transferred to a clear glass autosampler vial (Thermo Fisher Scientific, MA, USA), refilling it to $2 \mathrm{~mL}$ with paraffin oil and adding $\mathrm{C}_{22} \mathrm{H}_{46}$ as an internal standard. A 2-mL mixture of paraffin oil and ocimene was treated in the same way, representing a "before-evaporation" sample. Both of these samples were analyzed using gas chromatography-mass spectrometry (GC-MS). The samples were analyzed on a Trace Ultra GC (Thermo Fisher Scientific, MA, USA), which was equipped with a Restek Rxi (1 ms column; $30 \mathrm{~m}$ length; $0.25 \mathrm{~mm}$ ID; $0.25 \mathrm{~mm}$ film thickness) and connected to a TSQ mass spectrometer (Thermo Fisher
Scientific, MA, USA). The injector temperature was set to $250{ }^{\circ} \mathrm{C}$, and the oven was programmed to hold for $1 \mathrm{~min}$ at $40{ }^{\circ} \mathrm{C}$ then ramp to $300{ }^{\circ} \mathrm{C}$ at $15^{\circ} \mathrm{C} / \mathrm{min}$.

Internal standards were used to control for injection volume when comparing gas chromatogram peaks between samples. The peaks for the internal standard in the samples were nearly identical, so the heights of the gas chromatogram peaks for ocimene were used to determine the difference in ocimene concentration before and after evaporation. This analysis determined that $10 \%$ of the ocimene evaporated into the hive $(0.1 \mathrm{~mL})$ using the same exposure duration and temperature found in experimental colonies.

According to previous studies, larvae produce the highest amounts of EBO (18 ng/larva/20 min) in the first three larval stages (Maisonnasse et al. 2010). This means that an application of $0.1 \mathrm{~mL}$ of synthetic $(E)-\beta$ ocimene under our experimental conditions is approximately equivalent to the amount that $15,000-50,000$ young honey bee larvae would produce in 1 day (Maisonnasse et al. 2010). Honey bee queens lay an average of 2000 eggs per day (Page and Erickson 1988) but have the ability to lay 4000 or more eggs per day at peak productivity (Page and Metcalf 1984). Thus, a large productive colony may have up to 12,000 larvae in the first three larval instars at any given time. While the amount of synthetic pheromone used in the present study is relatively high, it is consistent with the ratio of larval equivalents of pheromone to number of focal bees used in previous studies to demonstrate the effects of EBO on worker physiology (see Maisonnasse et al. 2009).

\subsection{Statistical analysis}

All statistical analyses were performed in R (v 3.0.2) using the car, lmerTest, and lme4 packages (R Core Team 2014; Fox and Weisberg 2011; Kuznetsova et al. 2013; Bates et al. 2013). All foraging data was analyzed using repeated-measures ANOVA on a generalized linear mixed model with (a) number of pollen, non-pollen, or total foragers as response variables; (b) pheromone treatment and elapsed time since treatment as predictor variables; and (c) hive identity (subject) and date as random effects. Tukey's post hoc test was used to separate means for significant effects. A generalized linear mixed model was used to incorporate a Poisson distribution for count data. To correct for overdispersion, an observation-level random effect was 
included (Atkins et al. 2013). Error bars used in the figures represent within-subject standard error of the mean (Morey 2008).

To account for differences between experiments conducted during mornings vs. afternoons, or in early July vs. late July, these factors were included in the model as fixed effects. Because foraging activity was sampled once per hour for a total of $4 \mathrm{~h}$ after a treatment, we also included in the model elapsed time since exposure as a variable. If there was no significant difference between morning and afternoon foraging activity on a given trial, morning and afternoon data were pooled based on time elapsed since pheromone treatment removal. Similarly, observations from the two trials were pooled if there were no statistical differences between observations between early and late July.

In a separate analysis, we incorporated a binomial distribution to determine whether the ratio of pollen to non-pollen foragers changed in response to pheromone exposure. In this analysis, pollen foragers were treated as "successes" out of the total number of foragers counted per trial, but the same fixed and random effects were used as above.

\section{RESULTS}

We used a generalized linear mixed model (GLMM) and ANOVA to analyze total foraging activity and to compare pheromone treatment and control groups. After model reduction, there were statistically significant differences in total foraging activity due to pheromone treatment $\left(F_{1,355}=11.57, P=7.45 \times 10^{-4}\right)$, elapsed time since exposure $\left(F_{4,352}=4.97, P=6.5 \times 10^{-4}\right)$, and the interaction of trial (i.e., early July vs. late July) and pheromone exposure $\left(F_{2,354}=4.97\right.$, $\left.P=2.02 \times 10^{-3}\right)$. There were no significant effects due to morning vs. afternoon periods $\left(F_{2,352}=2.26, P=0.06\right)$ or due to trial $\left(F_{2,352}=0.20, P=0.94\right)$, so data from the two trials and two periods were pooled for total foraging activity. On average, colonies exposed to EBO treatment had $88.6( \pm 2.3)$ foragers per 5-min observation period while colonies exposed to control treatment had $95.2( \pm 3.4)$ foragers per 5-min observations.

To better understand the effect of synthetic pheromone on foraging, we then analyzed pollen foraging and non-pollen foraging separately, also using GLMM and ANOVA. Pollen foraging was higher in colonies treated with EBO compared to those treated with a paraffin-only control, but not significantly $\left(F_{1,355}=0.69, P=0.41\right)$. However, there was a statistically significant effect of time of day (Figure 1; ANOVA $F_{1,355}=51.8$, $P=3.69 \times 10^{-12}$; Tukey's post hoc test $P=0.026$ ) and trial (early vs. late July; $F_{1,355}=13.1$, $P=3.44 \times 10^{-4}$ ), independent of pheromone treatment, so data collected in the morning and afternoon were not pooled (Figure 1).

In contrast, non-pollen foraging was significantly higher in the pheromone treatment than the control treatment (Figure 2; ANOVA $F_{1,355}=5.57, P=1.8 \times 10^{-2}$; Tukey's post hoc test $P=0.016$ ). As in the case of pollen foraging, there was a significant effect of elapsed time since exposure $\left(F_{2,352}=2.38\right.$, $P=0.05)$, although there was no statistically significant interaction between pheromone treatment and time $\left(F_{4,352}=0.24, P=0.91\right)$. This indicates that significant differences in total foraging activity due to pheromone treatment may be driven mainly by nonpollen foraging activity.

In a separate analysis, we tested whether the ratio of pollen to non-pollen foragers differed between treatments by incorporating a binomial distribution instead of a Poisson distribution in the GLMM. There was no difference in the ratio of pollen to non-pollen foragers between pheromone-treated hives and control hives $\left(F_{1,355}=0.32, P=0.57\right)$.

Interestingly, foragers were more active during some times of the day than others. For example, colonies foraged for more pollen in the early morning than at any other time of day (Figure 1 and Electronic Supplementary Material), irrespective of treatment. Because we allowed bees to forage naturally, it was not possible to distinguish whether patterns of foraging activity over the course of a day were due to our treatments, or were at least in part due to variation in floral resource availability.

The synthetic ocimene that was used in this study was a mixture of three isomers, and it is not clear from the chromatogram which peak corresponded specifically to $(E)-\beta$-ocimene. 


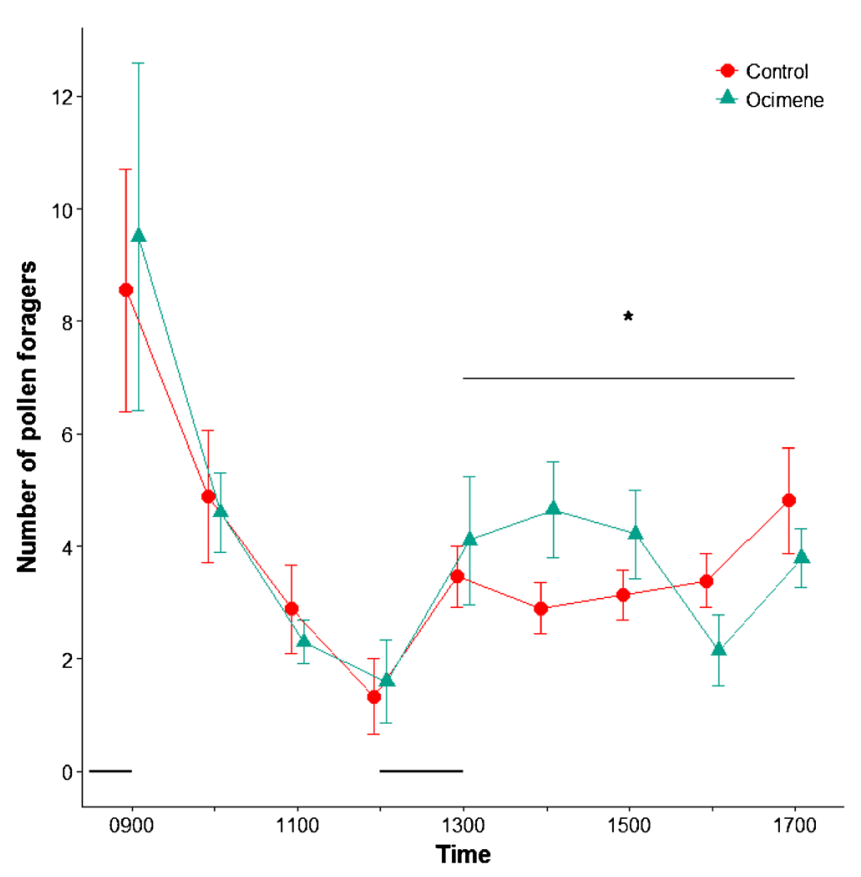

Figure 1. Average ( \pm SEM) number of pollen foragers returning to colonies within a 5-min interval after the addition of an ocimene pheromone treatment (triangle) or a paraffin oil control (circle). Observations began after administering a 1-h pulse of either ocimene or paraffin-only control at 0900 hours for morning trials and at 1200 hours for afternoon trials. Horizontal bars represent the time during which EBO was administered. Foraging activity differed significantly between morning and afternoon trials independent of pheromone treatment (ANOVA, $P<0.001$ ), which is indicated by an asterisk.

There were three isomers present in the chromatogram, so approximately one quarter to one half of the total ocimene present in the sample corresponded to $(E)$ - $\beta$-ocimene specifically. In addition, it is not clear whether honey bee workers are able to detect or distinguish between other ocimene isomers or whether natural larval pheromone contains other isomers.

\section{DISCUSSION}

When exposing whole colonies of naturally foraging honey bees to synthetic $(E)-\beta$ ocimene (EBO) in the presence of natural levels of honey bee brood, exposure to EBO moderately but significantly increases nonpollen foraging in experimental colonies. These observations are consistent with the hypothesis of Maisonnasse et al. (2010) that workers are able to monitor the prevailing
EBO concentration in the colony and adjust their foraging behaviors accordingly. Because EBO is a volatile pheromone that dissipates quickly, EBO concentrations in the hive may have a "releaser" effect on foragers, acting as a rapid indicator of the number of young larvae in the colony and, therefore, also of the brood's nutritional demands. We posit that foragers are thus able to sense and respond to the amount of young EBO-emitting larvae currently present in the hive and that this ability may help scale the colony's foraging effort with the cumulative nutritional demands of the brood.

It is well known that foraging activity in honey bee colonies depends on the amount of brood and stored food resources (Allen and Jeffree 1956; Free 1967; Fewell and Winston 1992; Fewell and Page 1993). Recently, Traynor et al. (2015) investigated the role that brood of different ages have on foraging activity, including a comparison of colonies with young larvae, broodless colonies 

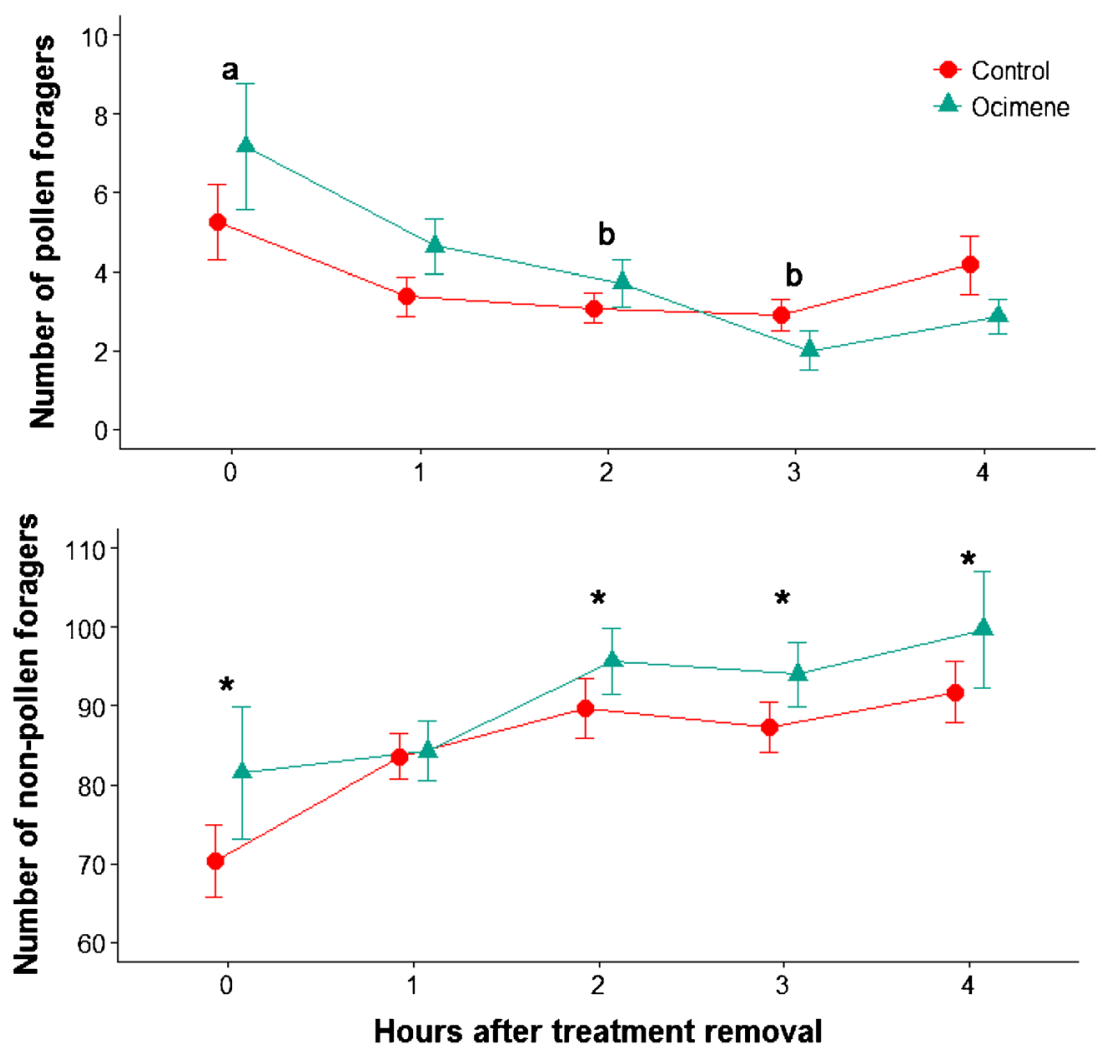

Figure 2. Average ( \pm SEM) number of pollen (top) or non-pollen foragers (bottom) returning to honey bee colonies within a 5-min interval after the addition of either an ocimene pheromone treatment or a paraffin oil control. The xaxis represents the number of hours after treatment pulse, either with ocimene (triangle) or a control (circle). Exposure to ocimene significantly increased non-pollen foraging activity compared to paraffin oil controls (ANOVA, $P \leq 0.05$ ). Pollen foraging showed moderate increases before returning to pre-treatment baseline levels $3 \mathrm{~h}$ after pheromone treatment. For pollen foraging, different letters represent time points with significantly different foraging activity, independent of pheromone treatment (post hoc Tukey's tests $P=0.026$ and $P=0.001$ respectively). For non-pollen foraging, asterisks indicate significant differences in foraging activity based on post hoc Tukey's tests $(P \leq 0.05)$.

exposed to 10,000 larval equivalents of synthetic ocimene, and broodless colonies exposed to a paraffin oil control. Traynor et al. found that, relative to colonies without brood, exposure to ocimene increased both total foraging activity and the proportion of foragers that gathered pollen. The present study, which focuses on the effects of EBO treatment that supplement the brood already present in the colony, found that in the presence of real brood, there is no difference in either pollen foraging or the proportion of pollen foraging when ocimene is added to the colony. Since the absence of real brood has a pronounced effect on foraging behavior (Camazine 1993), our results represent a closer approximation to the effect of EBO in a natural colony odor environment compared to studies using EBO in colonies without brood present. Overall, there is an accumulating body of evidence, including our own data, that the relative proportion of young and old brood plays an important role in regulating foraging activity and that the process is mediated by larval pheromones.

Previous studies on larval pheromones in honey bees have been unsuccessful in determining their mode of transmission from brood to adult workers. Pankiw et al. (1998) assayed foraging behavior in response to brood pheromone (BP) 
and found support for the idea that foragers could assess BP directly, though the authors could not rule out the possibility that nurse-forager interactions mediated BP-induced foraging behavior. That particular study used hexane extracts of young brood (2nd-4th larval instars), so EBO could have been a component in the larval extract tested. Later studies using synthetic BP or its individual ester components similarly could not distinguish whether foragers assessed BP directly or nurse bees transferred BP to foragers (Pankiw and Page 2001; Metz et al. 2010). In our study, we prevented bees from directly contacting experimental chemicals by applying either the pheromone or control treatments in petri dishes covered with wire mesh. Because workers did not come in direct contact with the EBO in treated colonies, it follows that physical transfer of larval signals to nurses is not required to elicit behavioral changes in foragers. Presently, we cannot determine whether foragers respond to EBO directly or whether nurses act as a relay to transduce the EBO signal to foragers, however. Regardless of the route, larvae potentially have a line of communication with foragers, and a larval-derived cue can play a modulatory role in determining the rate of non-pollen foraging, but not pollen foraging.

The effects we observed of ocimene on worker foraging behavior were moderate, indicating that, in our experimental paradigm at least, increases in EBO were not sufficiently potent to elicit a drastic increase in foraging rate. There may be two mutually non-exclusive explanations for why we observed moderate effects of EBO on foraging activity. First, the collective foraging rate of workers may be contingent upon additional colony cues (both within and outside the hive), with EBO typically acting in concert with these other cues to determine the foraging rate. For example, EBO may function in combination with, or augment the effects of, brood pheromone (BP), the levels of which were not assayed in our study. Secondly, in our experimental setup, it is possible that the baseline foraging rate in our control and experimental hives was already high for small nucleus hives so that the effects of treatment with EBO were constrained by the colony's intrinsic high foraging rate. Hence, although we have presented evidence for a modulatory effect of EBO on worker foraging, it remains possible that stronger effects could be observed in hive contexts that differ from our experimental setup. Furthermore, while we have focused on foraging rate exclusively, how EBO influences the diversity of other honey bee behaviors throughout the hive remains to be tested.

As a volatile pheromone, EBO diffuses quickly throughout the hive, dissipating over time and diminishing in salience. Such an ephemeral cue could act as a releaser that allows foragers to rapidly detect larval presence and nutritional state (i.e., hunger), especially if larvae can modulate the rate of pheromone production or release. Each hive received a 1-h pulse of either EBO or a paraffin oil control, so the concentration of EBO in the hive environment peaked during the initial pheromone pulse and dissipated after its removal. Foragers were therefore exposed to less EBO in the hive after each successive hour of the experiment, and so activity would be predicted to be the highest immediately after pheromone treatment. Indeed, pollen foraging showed peak activity directly after pheromone treatment (especially in the afternoon), followed by a gradual decrease back to baseline pre-treatment levels of foraging (Figure 2). We did not observe a gradual decrease in foraging activity for non-pollen foragers, though our time course may have been too short to capture any drop in non-pollen foraging activity. While increasing foraging has clear benefits for colony growth, the ability to quickly downregulate foraging activity can also be beneficial for colony function. For example, honey bees have been shown to reduce pollen foraging when pollen stores are high (Free 1967; Fewell and Winston 1992) and avoid floral patches when predation risks are high (Tan et al. 2013).

Pheromones are important in understanding the evolution and maintenance of eusociality in honey bees, which is defined by reproductive division of labor, overlapping generations, and cooperative brood care (Le Conte and Hefetz 2008; Bourke 2011). The work that has been done so far on the roles of EBO in honey bee colonies (including our own) suggests that EBO influences each of these defining characteristics of eusociality. For instance, previous studies have shown that EBO suppresses worker ovary development and 
accelerates the behavioral transition of workers from nurses to foragers (Maisonnasse et al. 2009, 2010). Furthermore, EBO helps to maintain reproductive division of labor, as it suppresses worker ovary activation, ensuring the presence of overlapping generations by modulating behavioral transitions among castes and encouraging cooperative brood care by regulating foraging (Maisonnasse et al. 2009, 2010).

As discussed previously, brood pheromone plays many of the same roles as EBO, which begs the question: why are there two distinct sets of pheromones that elicit performance of similar colony functions? Previous authors have suggested that brood pheromone and EBO could be targeted to different subsets of workers in the hive, though this has not been tested. In the context of queen pheromones for example, it has been argued that functional redundancy or reinforcement in pheromone communication is expected to evolve when the cost of reproductive conflict is high (Pankiw 2004; Slessor et al. 2005; Kocher and Grozinger 2011). These potential costs include miscommunication, which exacerbates conflict, or failure of communication, which could result in colony dysfunction. If the production of BP and EBO is considered in the context of functional redundancy or reinforcement of a cue or signal, perhaps EBO production played a role in both the evolution and the maintenance of sociality in honey bees by suppressing worker ovary development, reinforcing the reproductive dominance of the queen, and reducing within-colony conflict over reproduction.

Future studies should investigate the relationships between BP and EBO, between foraging activity and larval pheromone concentration, and between larval pheromone production and larval nutritional state. Because young brood are fed with royal jelly while older brood are fed with a mix pollen and glandular secretions, foragers could use the relative levels of BP and $\mathrm{EBO}$ to determine the current nutritional demands of the colony, especially if they are also able to sense availability of stored food resources. Future studies should also investigate the effect of EBO on the behaviors of workers performing other important hive functions (e.g., nursing, guarding) throughout the hive as well as its applications in promoting colony health and growth.

\section{ACKNOWLEDGMENTS}

We thank E.T. Ash for field assistance; I. Riddington at the Mass Spectrometry Facility (Department of Chemistry, University of Texas) for assistance with GC-MS analyses; and members of the Mueller Lab at The University of Texas at Austin, J. Parker, and two anonymous reviewers for detailed comments on the manuscript. This study was supported in part by Texas AgriLife Research Hatch Project TEX09557 awarded to JR; and grants from the Graduate Program in Ecology, Evolution, \& Behavior at The University of Texas at Austin, the Texas Ecolab program, and a National Science Foundation Graduate Research Fellowship (DGE1110007) to RM.

Evaluation du rôle du $\beta$-ocimène dans la régulation du comportement d'approvisionnement de l'abeille, Apis mellifera

phéromone larvaire / activité d'approvisionnement / pollen / phéromone synthétique / volatilité

Untersuchung der Rolle von $\beta$-Ocimen in der Regulierung des Sammelverhaltens der Honigbiene, Apis mellifera

Apis mellifera / Honigbienensammelverhalten / synthetisches Pheromone / $\beta$-Ocimen / Flüchtigkeit

\section{REFERENCES}

Alaux, C., Le Conte, Y., Adams, H.A., Rodriguez-Zas, S., Grozinger, C.M., Sinha, S., Robinson, G.E. (2009) Regulation of brain gene expression in honey bees by brood pheromone. Genes Brain Behav. 8(3), 309-319

Allen, M.D., Jeffree, E.P. (1956) The influence of stored pollen and of colony size on the brood rearing of honey bees. Ann. Appl. Biol. 44 (4), 649-656

Atkins, D.C., Baldwin, S.A., Zheng, C., Gallop, R.J., Neighbors, C. (2013) A tutorial on count regression and zero-altered count models for longitudinal substance use data. Psychol. Addict. Behav. 27, 166-77

Bates, D., Maechler, M., Bolker, B., Walker, S. (2013) lme4: Linear mixed-effects models using Eigen and S4. R package version 1.0-5. http://CRAN.Rproject.org/package $=\operatorname{lme} 4$ 
Bourke, A. (2011) Principles of Social Evolution. Oxford University Press, London

Camazine, S. (1993) The regulation of pollen foraging by honey bees: how foragers assess the colony's need for pollen. Behav. Ecol. Sociobiol. 32 (4), 265-272

Crailsheim, K., Schneider, L.H.W., Hrassnigg, N., Bühlmann, G., Brosch, U., Gmeinbauer, R., Schöffmann, B. (1992) Pollen consumption and utilization in worker honeybees (Apis mellifera carnica): dependence on individual age and function. J. Insect Physiol. 38, 409-419

Fewell, J.H., Page, R.E. (1993) Genotypic variation in foraging responses to environmental stimuli by honey bees, Apis mellifera . Experientia 46, 1106-1112

Fewell, J.H., Winston, M.L. (1992) Colony state and regulation of pollen foraging in the honey bee, Apis mellifera L. Behav. Ecol. Sociobiol. 30, 387-393

Fox, J., Weisberg, S. (2011) An \{R\} Companion to Applied Regression, 2nd edn. Sage, Thousand Oaks

Free, J.B. (1967) Factors determining the collection of pollen by honeybee foragers. Anim. Behav. 15(1), 134-144

Kocher, S.D., Grozinger, C.M. (2011) Cooperation, conflict, and the evolution of queen pheromones. J. Chem. Ecol. 37, 1263-75

Kuznetsova, A., Brockhoff, P.B., Christensen, R.H.B. (2013) lmerTest: Tests for random and fixed effects for linear mixed effect models (lmer objects of lme4 package). R package version 2.0-0. http://CRAN.Rproject.org/package $=$ lmerTest

Le Conte, Y., Arnold, G., Trouiller, J., Masson, C. (1990) Identification of a brood pheromone in honeybees. Naturwissenschaften 81, 462-465

Le Conte, Y., Sreng, L., Trouiller, J. (1994) The recognition of larvae by worker honeybees. Naturwissenschaften. 81, 462-465

Le Conte, Y., Arnold, G., Trouiller, J., Masson, C., Chappe, B., Ourisson, G. (1989) Attraction of the parasitic mite Varroa to the drone larvae of honey bees by simple aliphatic esters. Science 245 (4918), 638-639

Le Conte, Y., Mohammedi, A., Robinson, G.E. (2001) Primer effects of a brood pheromone on honeybee behavioural development. Proc. R. Soc. London B. 268, 163-168

Le Conte, Y., Hefetz, A. (2008) Primer pheromones in social hymenoptera. Annu. Rev. Entomol. 53 , 523-42

Maisonnasse, A., Lenoir, J., Beslay, D., Crauser, D., Le Conte, Y. (2010) E- $\beta$-ocimene, a volatile brood pheromone involved in social regulation in the honey bee colony (Apis mellifera). PLoS One 5, 1-7

Maisonnasse, A., Lenoir, J., Costagliola, G., Beslay, D., Choteau, F., Crauser, D., Becard, J., Plettner, E., Le Conte, Y. (2009) A scientific note on E- $\beta$-ocimene, a new volatile primer pheromone that inhibits worker ovary development in honey bees. Apidologie 40 , 562-564

Metz, B.N., Pankiw, T., Tichy, S.E., Aronstein, K.A., Crewe, R.M. (2010) Variation in and responses to brood pheromone of the honey bee (Apis mellifera L.). J. Chem. Ecol. 36, 432-40

Morey, R.D. (2008) Confidence intervals from normalized data: A correction to Cousineau (2005). Tutorials Quant. Meth. Psych. 4(2), 61-64

Muenz, T.S., Maisonnasse, A., Plettner, E., Le Conte, Y., Rössler, W. (2012) Sensory reception of the primer pheromone ethyl oleate. Naturwissenschaften 99, $421-5$

Page, R.E., Erickson, E.H. (1988) Reproduction by worker honey bees (Apis mellifera L.). Behav. Ecol. Sociobiol. 23, 117-126

Page, R.E., Metcalf, R.A. (1984) A population investment sex ratio for the honey bee (Apis mellifera L.). Am. Nat. 124, 680-702

Pankiw, T., Page, R.E., Fondrk, M.K. (1998) Brood pheromone stimulates pollen foraging in honey bees (Apis mellifera). Behav. Ecol. Sociobiol. 44, 193198

Pankiw, T., Page, R.E. (2001) Brood pheromone modulates honeybee (Apis mellifera L.) sucrose response thresholds. Behav. Ecol. Sociobiol. 49, 206-213

Pankiw, T. (2004) Cued in : honey bee pheromones as information flow and collective decision-making. Apidologie 35, 217-226

Pankiw, T., Rubink, W.L. (2002) Pollen foraging response to brood pheromone by Africanized and European honey bees (Apis mellifera L.). Ann. Entomol. Soc Am 95(6), 761-767

R Core Team (2014) R: A language and environment for statistical computing. R Foundation for Statistical Computing, Vienna. http://www.R-project.org/

Sagili, R.R., Pankiw, T., Metz, B.N. (2011) Division of labor associated with brood rearing in the honey bee: how does it translate to colony fitness? PLoS One . doi:10.1371/journal.pone.0016785

Slessor, K.N., Winston, M.L., Le Conte, Y. (2005) Pheromone communication in the honeybee (Apis mellifera L.). J. Chem. Ecol. 31, 2731-45

Tan, K., Hu, Z., Chen, W., Wang, Z., Wang, Y., Nieh, J.C. (2013) Fearful foragers: honey bees tune colony and individual foraging to multi-predator presence and food quality. PloS One . doi:10.1371/journal.pone.0075841

Traynor, K.S., Le Conte, Y., Page , R.E. (2015) Age matters: pheromone profiles of larvae differentially influence foraging behavior in the honeybee, Apis mellifera. Anim. Behav. 99, 1-8

Winston, M.L. (1987) The biology of the honey bee. Harvard University Press, Cambridge 